\title{
Analysis of Commercial Hand Sanitisers amid CoViD-19: Are We Getting the Products that We Need?
}

\author{
Alberto Berardi, ${ }^{1}$ Beniamino Cenci-Goga, ${ }^{2}$ Luca Grispoldi, ${ }^{2}$ Lina Cossignani, ${ }^{3,5}$ and Diego Romano Perinelli, ${ }^{4,5}$ (D)
}

Received 4 August 2020; accepted 14 September 2020; published online 15 October 2020

\begin{abstract}
The CoViD-19 pandemic has caused a sudden spike in demand and production of hand sanitisers. Concerns are rising regarding the quality of such products, as the safeguard of consumers is a priority worldwide. We analyse here the ethanolic content of seven off-the-shelf hand sanitiser gels (two biocides and five cosmetics) from the Italian market, using gas chromatography. The WHO recommends that products containing ethanol should have $60-95 \%$ (v/v) alcohol. Four of the tested hand gels have ethanolic contents within the recommended range, while three products (all cosmetics) contain $<60 \%(\mathrm{v} / \mathrm{v})$, i.e. $52.1 \%(\mathrm{w} / \mathrm{w})$, ethanol. The product with the lowest alcoholic content has $37.1 \% \mathrm{w} / \mathrm{w}$ ethanol. Toxic methanol is not found in any of the hand sanitisers. We show, in addition, that products with the highest ethanolic content have generally greater antibacterial activity. In conclusion, all tested products are complying with the EU regulations, as the three "substandard" products are classified as cosmetics, whose purpose is cleaning and not disinfecting. Nevertheless, if such hand cleaners were inappropriately used as hand disinfectants, they might be ineffective. Thus, consumer safety relays on awareness and ability to distinguish between biocidal and cosmetics hand gels. The obtained results might sensitise the scientific community, health agencies and ultimately consumers towards the risks of using hand sanitisers of substandard alcoholic concentration. If the wrong product is chosen by consumers, public health can be compromised by the inappropriate use of "low-dosed" cosmetic gels as disinfectants, particularly during the period of the CoViD-19 pandemic.
\end{abstract}

KEY WORDS: alcohol content; gas chromatography; ethanol-based disinfectants; antimicrobial; CoViD19.

\section{INTRODUCTION}

At the beginning of 2020, a new coronavirus, namely SARS-CoV-2, has started to spread worldwide leading to the so-

Alberto Berardi and Beniamino Cenci-Goga are co-first authors.

Guest Editor: Claudio Salomon

Electronic supplementary material The online version of this article (https://doi.org/10.1208/s12249-020-01818-6) contains supplementary material, which is available to authorized users.

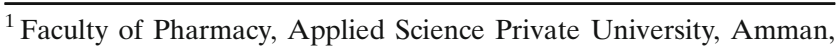
11931, Jordan.

${ }^{2}$ Department of Veterinary Medicine, University of Perugia, via San Costanzo, 4, 06126, Perugia, Italy.

${ }^{3}$ Department of Pharmaceutical Sciences, University of Perugia, via S. Costanzo, 06126, Perugia, Italy.

${ }^{4}$ School of Pharmacy, University of Camerino, 62032, Camerino, MC, Italy.

${ }^{5}$ To whom correspondence should be addressed. (e-mail: lina.cossignani@unipg.it; diego.perinelli@unicam.it)
}

called CoViD-19 pandemic (1). Considering that SARS-CoV-2 is an air-born pathogen but can also spread through surfaces, hand sanitisation has become a primary infection prevention measure (2). As health agencies around the world have started to recommend the use of alcohol-based hand rubs (ABHRs), the demand and sale of such products skyrocketed, leading to sudden shortages of this commodity in most markets (3).

In Europe, many businesses have increased their production of ABHRs, while others have even shifted their manufacturing lines to ABHRs (4). In this run to produce hand sanitisers, the risk of substandard products being introduced into the market could be a reality. The European Community (EC) stated that "a steep increase in the submission to the Cosmetics Product Notification Portal" was notified to the EC, urging the issue of a clear guidance on legislation for production of leave-on hand cleaners and hand disinfectants (4). It is emphasised in this guidance that hand sanitisers aiming at protecting public health by disinfecting should follow the legislation of biocidal products. Cosmetic 
hand sanitisers are instead supposed to clean and not disinfect. Thus, companies must be aware that "hand disinfectants" are subject to rules established under the biocidal products - and not cosmetics products-regulation.

Individuals from the general public are unlikely to distinguish between cosmetic and biocidal hand sanitisers. If a cosmetic ABHR is used improperly for the purpose of disinfection, then this product becomes, practically, a substandard product. Disinfection in ABHRs is dependent on alcoholic concentration. Health agencies recommend that hand disinfectants must contain $60-95 \%$ (v/v) ethanol (5-7). Keeping this alcoholic range as the reference concentration to ensure disinfection efficacy there is a risk that cosmetic products, which are not disinfectants but might be improperly used as disinfectants, do not need to have the alcoholic concentration stated in the label and could contain ethanol in concentrations lower than the aforementioned range. In this case, the product may not be effective in killing pathogenic microorganisms. We reached this conclusion in our recently published review on hand sanitisers (3), provoking further questions that inspired the current original research. These new questions that we address here are as follows: (i) do biocidal hand sanitisers contain as much ethanol as stated in the label? and (ii) what is the actual ethanolic content in cosmetic hand sanitisers (being not mandatorily reported in the label)? Is the ethanolic content within or below the range recommended by health agencies to ensure disinfection?

In view to ultimately safeguard consumers, we probe here the concentration of ethanol in seven commercial ethanol-based hand sanitiser gels purchased in the Italian market, two biocides and five cosmetic products, comparing the obtained results with label claims. We also assess their antibacterial properties as a preliminary result of their potential disinfection ability.

\section{MATERIALS AND METHODS}

\section{Materials}

The ethanol concentration ( $\% \mathrm{w} / \mathrm{w})$ and the antimicrobial activity of seven different ABHRs was evaluated. The composition (according to label claims) and regulatory classification of the analysed alcohol gels are reported in Table I. All products were purchased from a local pharmacy, except for Gel 4, which was purchased in a local supermarket.

\section{Determination of Ethanolic Concentration}

Ethanol was extracted from samples by headspace solidphase microextraction (HS-SPME) using a fibre coated with 85- $\mu \mathrm{m}$ polyacrylate film (Supelco, Bellefonte, PA, USA). Before use, the fibre was conditioned following the instructions of the manufacturer. An aliquot (500 mg) of each sanitising gel sample (1-7) and calibration standards was transferred to an 8-ml screw-capped amber vial with a PTFElined silicone septum. The vial was thermostated for $1 \mathrm{~min}$ at $30{ }^{\circ} \mathrm{C}$ before SPME extraction. The SPME fibre was inserted into the headspace of the vial through the septum on the screw cap, then it was exposed to the headspace of the vial for $20 \mathrm{~s}$ at $35^{\circ} \mathrm{C}$. After the extraction, SPME fibre was removed from the vial and inserted into the gas chromatograph (GC) injection system for the analysis.
A DANI 1000 DPC (Norwalk, CT, USA) GC provided with a split-splitless injector and a flame ionisation detector (FID) was used. The injector was set in splitless mode for $5 \mathrm{~min}$ and maintained at $250{ }^{\circ} \mathrm{C}$. A fused silica capillary column, Supelcowax-10 $(60 \mathrm{~m} \times 0.25 \mathrm{~mm}$ i.d., $0.25 \mu \mathrm{m}$ f.t.; Supelco, Bellefonte, PA, USA), was used for the chromatographic separation. The initial oven temperature, $65^{\circ} \mathrm{C}$, was raised at $6^{\circ} \mathrm{C} / \mathrm{min}$ to $155^{\circ} \mathrm{C}$, and then at $20^{\circ} \mathrm{C} / \mathrm{min}$ to $250^{\circ} \mathrm{C}$. The detector temperature was $260^{\circ} \mathrm{C}$. The carrier gas was helium with a flow rate of $1 \mathrm{ml} / \mathrm{min}$. The chromatograms were acquired and processed using Clarity integration software (DataApex Ltd., Prague, Czech Republic).

The external calibration curve for the quantification of ethanol was obtained by analysing standard gel samples at a different concentration of ethanol $(40-70 \% \mathrm{w} / \mathrm{w})$. These gels were prepared by dispersing Carbopol ${ }^{\circledR} 974(1 \%$ w/w) to the corresponding hydro-alcoholic mixture under stirring. The dispersions were left under stirring for $24 \mathrm{~h}$ and, then $\mathrm{pH}$ was adjusted to 7.0 using triethanolamine.

\section{Antimicrobial Test}

The antimicrobial activity was tested against two different bacterial strains: Staphylococcus aureus ATCC 29213 for gram positive and a clinical isolated Escherichia coli for gram negative. Each strain was grown aerobically in Nutrient Broth (NB; Oxoid, $\mathrm{UK})$ at $37^{\circ} \mathrm{C}$ for $24 \mathrm{~h}$. A preliminary assay was prepared in order to assess (i) the non-toxicity of the liquid culture media used for dilutions (maximum recovery diluent, MRD, Oxoid, UK) of bacterial suspension, (ii) the non-toxicity of the neutraliser (D/E Neutralising Broth; Liofilchem, Italy) and (iii) the non-toxicity of the different gels after neutralisation. In order to do so, bacterial suspensions and the different diluents were left in contact at $37^{\circ} \mathrm{C}$ for the test period. After this, decimal dilutions were performed, samples were inoculated in triplicate on Nutrient Agar (NA; Oxoid, UK) and incubated at $37^{\circ} \mathrm{C}$ for $24 \mathrm{~h}$. Counting was performed and the total viable cell count was calculated.

Vitality reduction activity was tested according to the BS EN 1040:2005 (European Committee for Standardization [ECS], 2005) as modified by Grispoldi et al. (8), using the tested neutraliser to stop the antibacterial activity of the gels at any given time. For the assay, sterile tubes were prepared with solutions of bacterial suspension and the hand sanitisers were diluted to different $\mathrm{v} / \mathrm{v}$ concentrations $(33 \%, 50 \%, 66 \%$ and $75 \%$ ). The solution was left in contact with the diluted ABHRs for $8 \mathrm{~min}$. Then, the appropriate volume of neutraliser was added. After $5 \mathrm{~min}$, the mixture decimal dilutions were prepared. Samples were inoculated in triplicate on NA and incubated at $37^{\circ} \mathrm{C}$ for $24 \mathrm{~h}$. Counting was performed and the total viable cell count was calculated. Only the plates showing a number of colonies included in a $1.510^{2}-3.010^{3}$ (maximum deviation of $10 \%$ ) were used to perform the result calculation (9).

\section{RESULTS}

\section{Ethanol Content Determination}

A simple and rapid analytical method, HS-SPME in combination with GC/FID, has been used for the extraction and quantification of ethanol in commercial hand sanitiser gels. The quantification of ethanol has been successfully 
Table I. The composition and regulatory classification of the analysed alcohol gels

\begin{tabular}{|c|c|c|c|}
\hline Entry & Composition & Ethanol* & Regulation \\
\hline Gel 1 & Ethanol $* * 66 \mathrm{~g}$; excipients and water up to $100 \mathrm{~g}$. & $66 \%$ & Cosmetic \\
\hline Gel 2 & Ethanol (96\%) $74 \mathrm{~g}$; excipients and water up to $100 \mathrm{~g}$. & $74 \%$ & Biocide \\
\hline Gel 3 & $\begin{array}{l}\text { Alcohol; water; isopropyl alcohol; glycerin; Hydroxypropyl Methyl Cellulose; Aloe barbadensis leaf juice; } \\
\text { parfum. }\end{array}$ & $\mathrm{N} / \mathrm{R}^{* * *}$ & Cosmetic \\
\hline Gel 4 & Water; Denatured alcohol; glycerin; parfum; carbomer; limonene; linalool; aminomethyl propanol. & $\mathrm{N} / \mathrm{R}$ & Cosmetic \\
\hline Gel 5 & Ethanol $70 \mathrm{~g}$; excipients and water up to $100 \mathrm{~g}$. & $70 \%$ & Biocide \\
\hline Gel 6 & $\begin{array}{l}\text { Denatured alcohol; water; propylene glycol; carbomer, glycerin; sodium hydroxide; citral; citronellol; geraniol; } \\
\text { hydroxycitronellal; linalool, limonene; CI } 42090 \text {. }\end{array}$ & $\mathrm{N} / \mathrm{R}$ & Cosmetic \\
\hline Gel 7 & $\begin{array}{l}\text { Denatured alcohol; water; aloe barbadensis leaf juice; citrus lemon peel oil; carbomer; propylene glycol; } \\
\text { triethanolamine; PEG-40 hydrogenated castor oil, limonene; sodium benzoate; potassium sorbate; citric acid. }\end{array}$ & $60 \%$ & Cosmetic \\
\hline
\end{tabular}

*The percentage of ethanol is w/w for the products authorised as biocide, while the unit is unknown, since not reported, for the cosmetic ones **Alcohols, as well as other ingredients with potential antimicrobial activity, are highlighted in bold

*** $N / R$ not reported

performed by external standard method, with good precision and linearity. Values of inter-assay coefficients of variation lower than $7.8 \%$ indicate that the technique is reproducible, while the calibration curve prepared by analysing standard gels with known content of ethanol shows linear relationship with highly significant $(p<0.01)$ correlation $(r=0.9971)$ (Fig. 1a). The concentration of ethanol (\% w/w) in the tested hand sanitiser gels ranges from $37.1 \pm 1.9 \% \mathrm{w} / \mathrm{w}$ (gel 6) to $66.1 \pm 2.0 \% \mathrm{w} / \mathrm{w}$ (gel 5). Three gels (gels 3, 4 and 6) have an average ethanolic content below the lower limit ( $60 \% \mathrm{v} / \mathrm{v}$, i.e. $52.1 \% \mathrm{w} / \mathrm{w}$ ) of the WHO recommended range (5), while four are within the recommended range. The highest ethanol concentration $(\geq 60 \% \mathrm{w} / \mathrm{w})$ was determined for gels 1,2 and 5. Among these, gel 2 and gel 5 are those authorised as biocides (Table I). No methanol was detected in any of the analysed gels (data not shown).

\section{Antimicrobial Activity of Alcoholic Gels}

After validation of the antimicrobial assay (for more information, see the supporting information), the antibacte- rial efficacy of the commercial gels was evaluated. The bactericidal activity of dilutions (from $33 \% \mathrm{v} / \mathrm{v}$ to $75 \% \mathrm{v} / \mathrm{v}$ ) of the seven commercial gels upon $8 \mathrm{~min}$ contact with $S$. aureus and E. coli is shown in Fig. 2. At a concentration of $33 \% \mathrm{v} / \mathrm{v}$, vitality reduction for $S$. aureus ranged between $0.25 \mathrm{cfu} \mathrm{ml}^{-1}$ (gel 4) and $4.91 \mathrm{cfu} \mathrm{ml}^{-1}$ (gel 2); the total viable cell count at the same concentration for E. coli was 0 for gel 2 and 7 , while the vitality reduction ranged between $0.2 \mathrm{cfu} \mathrm{ml}^{-1}$ (gel 1) and $0.46 \mathrm{cfu} \mathrm{ml}^{-1}$ (gel 5) for the other gels. At a concentration of $50 \% \mathrm{v} / \mathrm{v}$, the total viable cell count for $S$. aureus was 0 for gel 2 and 7, while the vitality reduction ranged between $0.24 \mathrm{cfu} \mathrm{ml}^{-1}$ (gel 3) and $7.53 \mathrm{cfu} \mathrm{ml}^{-1}$ (gel 5) for the other gels; at the same concentration, the total viable cell count for $E$. coli was 0 for gels $1,2,4,6$ and 7, while the vitality reduction was $0.5 \mathrm{cfu} \mathrm{ml}^{-1}$ for gel 3 and $8.11 \mathrm{cfu} \mathrm{ml}^{-1}$ for gel 5. At a concentration of $66 \% \mathrm{v} / \mathrm{v}$, viable cells were observed only for $S$. aureus in gels 3 and 4, while no viable cells were counted for the other gels; no viable cells were counted at the same concentration for E. coli. At a concentration of $75 \% \mathrm{v} / \mathrm{v}$, a complete reduction was observed for all the gels for both bacteria.
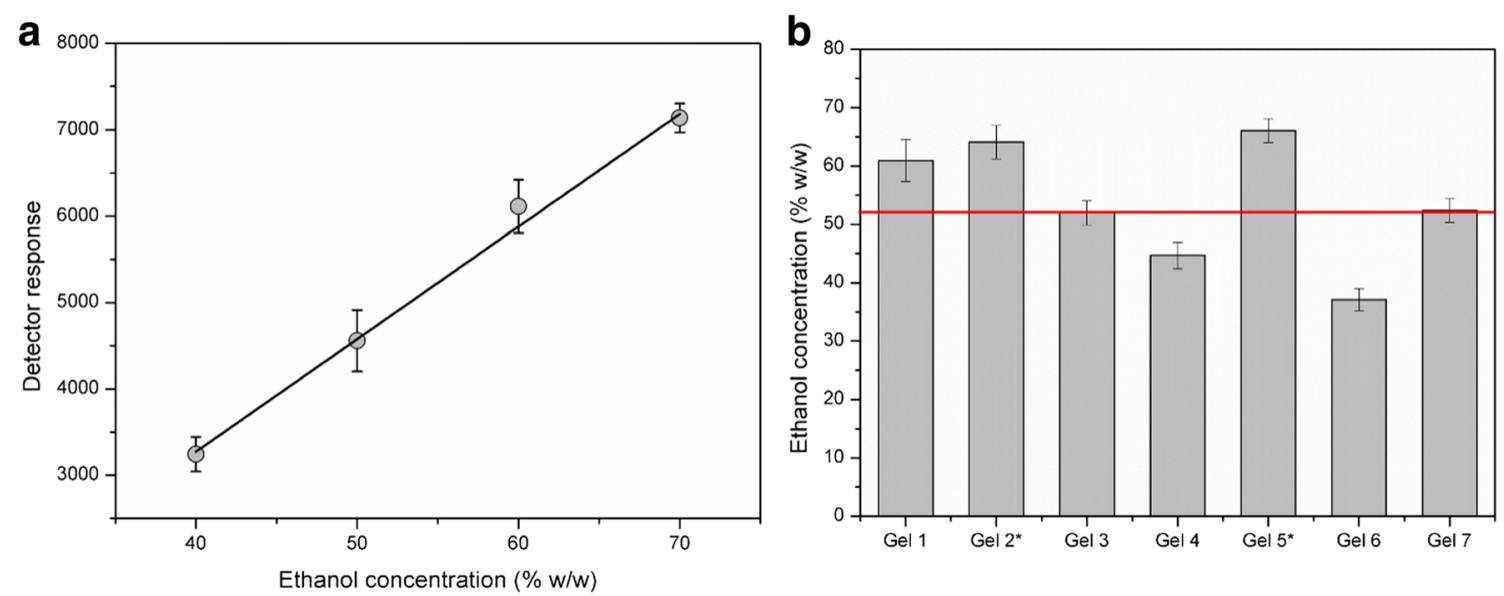

Fig. 1. GC/FID analysis of ethanolic content in the gels. a Calibration curve for the quantification of ethanol. The calibration curve was prepared by analysing Carbopol ${ }^{\circledR}$ gels with a standard concentration $(40-70 \% \mathrm{w} / \mathrm{w})$ of ethanol. b The concentration of ethanol (\% w/w) determined by GC/FID in the analysed hand sanitiser gels (1-7). The red line indicates the lower limit of the range of concentration of ethanol recommended by the WHO for hand sanitisers. "** indicates products that are biocides 
Gel 1

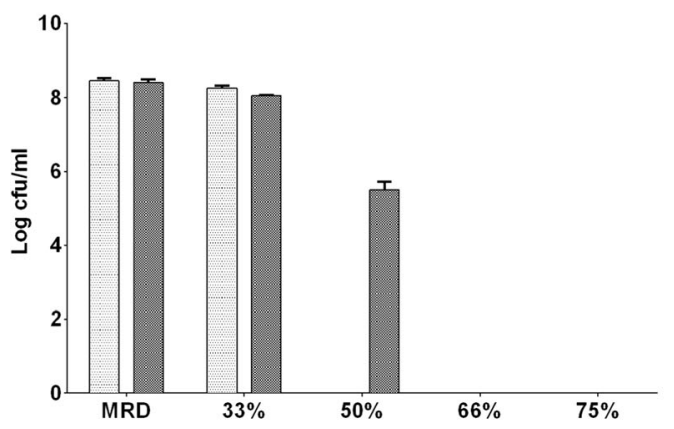

Gel 3

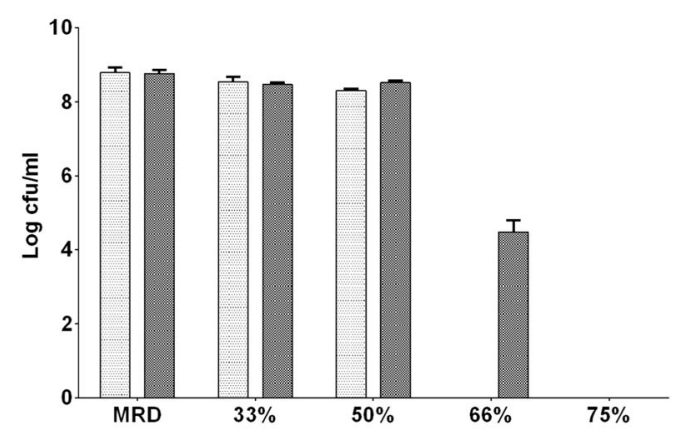

Gel 5

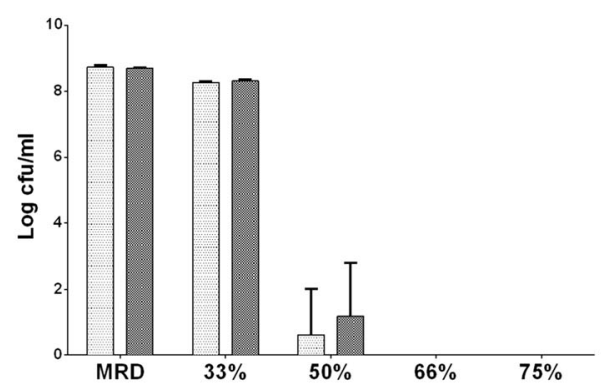

Gel 2
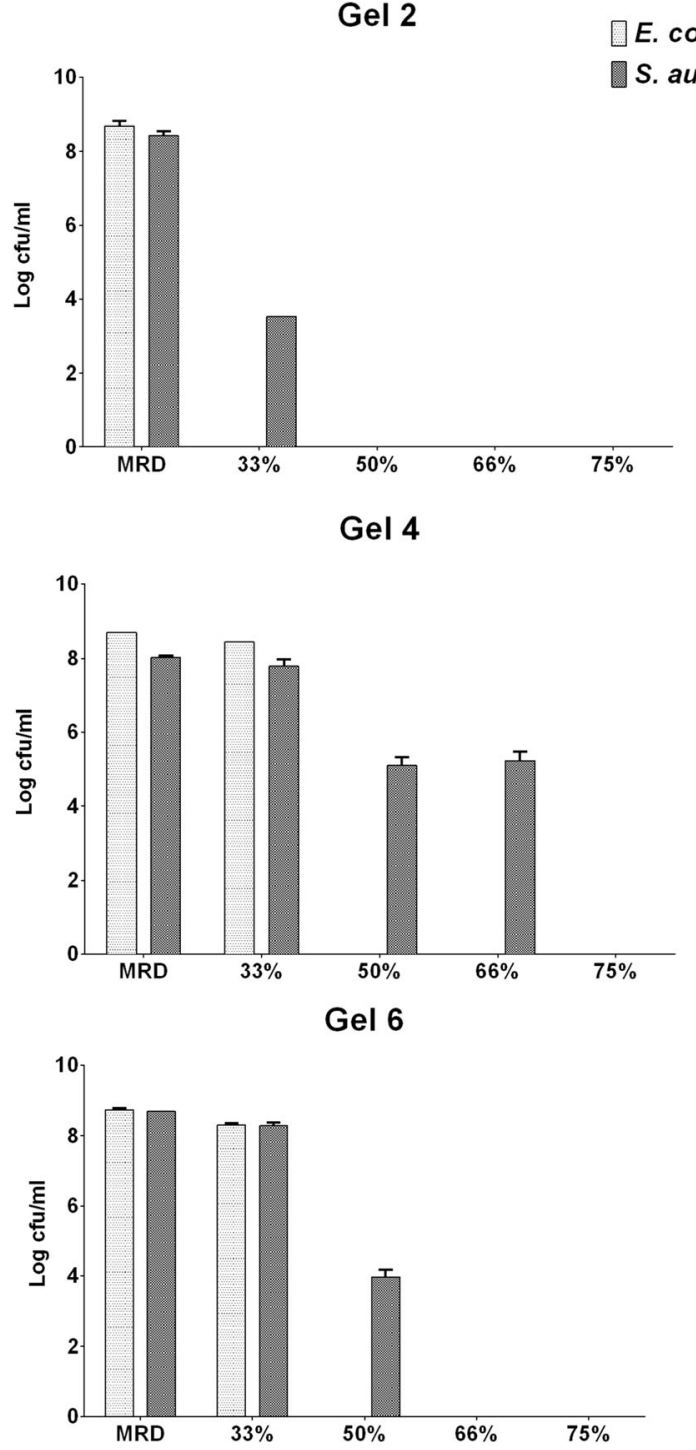

Gel 7

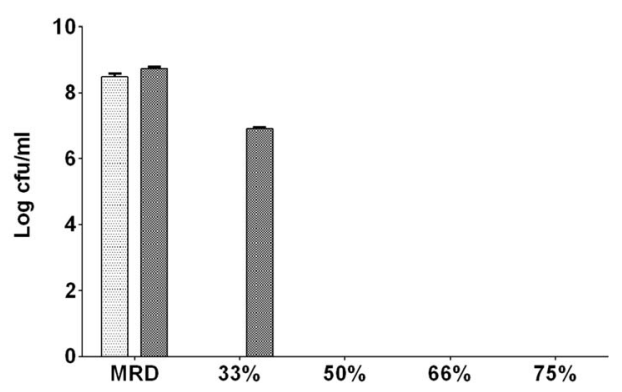

Fig. 2. Vitality reduction ( $\log \mathrm{cfu} / \mathrm{ml})$ for the model bacteria (E. coli and S. aureus) after contact with diluted (33-75\% v/v) hand sanitiser gel (1-7). MRD is the maximum recovery diluent used as negative control

\section{DISCUSSION}

The result of our analysis reveals that three of the seven ABHRs tested have ethanolic content below the range recommended by regulatory agencies (60 to $95 \% \mathrm{v} / \mathrm{v})(5-7)$. However, one of these gels, i.e. gel 3, contains' also isopropyl alcohol (Table I) in addition to $52 \%$ ethanol; thus, the overall alcoholic content of this product is likely to be within the expected range for disinfection.

The EU regulations for biocides (10) require that the concentration of the active (e.g. ethanol) should be stated in the label. Of the two tested biocides, gel 5 has $\approx 66 \%(\mathrm{w} / \mathrm{w})$ ethanol, against a label claim of $70 \%(\mathrm{w} / \mathrm{w})$, and gel 2 contained $\approx 64 \%$ (w/w) ethanol, against $74 \%$ (w/w; with 
ethanol $96 \%$, corresponding to $\approx 71 \%$ with absolute ethanol) of the label claim. Despite some discrepancy with the label claim, both biocides contain alcohol well within the range recommended by the health agencies. On the other hand, products containing "substandard" $(<60 \% \mathrm{v} / \mathrm{v})$ concentrations of ethanol, i.e. gels 3, 4 and 6, are all cosmetics (Table I). EU regulations on cosmetics require that all ingredients should be reported in the label (11), in descending order of weight, while there is no requirement to report the concentration of alcohol. Thus, also gels 3, 4 and 6 comply with EU regulations. Such products are, however, cosmetics to be used solely for cleansing purposes and not suitable for hand disinfection.

A question arises to whether consumers would be able to distinguish between two basically identical hand product types, which are biocidal hand gels and cosmetics hand gels (differing only for the label). Most probably many consumers are unable to choose the right product for the right purpose, with high chance that "under-dosed" (i.e. $<60 \% \mathrm{v} / \mathrm{v}$ of ethanol) cosmetic gels are improperly used by individuals who intend to disinfect their hands amid the CoViD-19 pandemic. This risk that cosmetic hand sanitisers might be sold and used inappropriately in place of disinfectants is not remote amid the CoViD-19 health crisis. Indeed, in April 2020, after witnessing a sharp increase in the submissions to the Cosmetics Product Notification Portal, a clarification for economic operators was deemed "urgently needed" by the European Commission (4). The "Guidance on the applicable legislation for leave-on hand cleaners and hand disinfectants (gel, solution, etc.)" was thus promptly issued.

It is worth noting that none of the ABHRs tested contains any trace of methanol. The issue of methanol contamination in ABHRs has been recently raised by the US FDA, which has issued a list of nearly 90 "do-not-use" dangerous hand sanitisers containing methanol. Among the tested products, methanol content ranged between 1 and $80 \%$ (12).

Given the stringent safety measures and difficulty in sourcing and handling SARS-CoV-2 virus, the antibacterial test of Fig. 2 aimed to provide some preliminary results on the intrinsic disinfection power of the tested ABHRs. It is worth noting that to better discriminate on the antibacterial activity, hand gels were tested diluted. In agreement with their high ethanolic content and regulatory classification, both biocides (gels 2 and 5) elicit strong antibacterial activity. Among the five cosmetics, the antibacterial activity is variable between products and not always directly related to the concentration of ethanol. For example, gel 7, which ranks fourth out of the seven gels in terms of ethanolic content, showed strong antibacterial effect. This can possibly be attributed to the presence of other ingredients in the formulations (e.g. preservatives and organic acids) that can have antimicrobial activity. For instance, citric acid (present in gel 7) can substantially increase viricidal activity of alcohol-based hand sanitisers (13) and it has also antibacterial activity (14). Overall, although ingredients other than alcohol can have an adjuvant antimicrobial effect, safe hand disinfection should rely exclusively on alcohol content. Health agencies discourage the use of all products other than those containing at least $60 \%(\mathrm{v} / \mathrm{v})$ alcohol (5). Scientists, as well, suggest not adding bactericidal agents to ABHRs as they do not add clear benefits (15), while some may increase the risk of antibiotic resistance (16). If and once virus-like particles of SARS-CoV2 will be ready available, future experimental work shall focus on the evaluation of the stability of these non-infectious viral mimics upon exposure to biocidal and cosmetics hand sanitisers.

In conclusion, we propose to answer the provocative question raised in the title of this article, i.e. to whether the hand sanitisers available in the market fulfil quality needs. We demonstrated that:

- $\quad$ The tested products fulfil the regulatory requirements specific to the class to which they belong (i.e. biocide or cosmetic).

- Yet, some cosmetic hand sanitisers, which alcoholic concentration is not stated in the label, contain ethanol (e.g. $\approx 40 \%$ ) well below the range of concentrations recommended by health agencies for infection prevention, thus following below expected standards of disinfection.

In the era of the CoViD-19 pandemic, when hand disinfection is deemed as a crucial infection prevention measure (3), having off-the-shelf cosmetic hand gels with sub-disinfecting concentrations of ethanol is concerning. How many from the general public are inadvertently using gels containing $\approx 40 \%$ ethanol as those tested here, expecting efficient disinfection? Such problem could perhaps be mitigated by awareness campaigns, appropriate pharmacists counselling and revisions of current regulations. A system could be introduced to require manufacturers of cosmetic ABHRs to add, for example, an extra label which states "not for disinfection" in a large and easily readable size.

\section{ACKNOWLEDGEMENTS}

AB is grateful to Dr. Hamid A. Merchant for sparking the motivation to develop this project.

\section{REFERENCES}

1. Zhu N, Zhang D, Wang W, Li X, Yang B, Song J, et al. A novel coronavirus from patients with pneumonia in China, 2019. N Engl J Med. Mass Medical Soc. 2020;382:727-33.

2. van Doremalen N, Bushmaker T, Morris DH, Holbrook MG, Gamble A, Williamson BN, et al. Aerosol and surface stability of SARS-CoV-2 as compared with SARS-CoV-1. N Engl J Med. Massachusetts Medical Society; 2020. Available from: https:// doi.org/10.1056/NEJMc2004973.

3. Berardi A, Perinelli DR, Merchant HA, Bisharat L, Basheti IA, Bonacucina G, et al. Hand sanitisers amid CoViD-19: a critical review of alcohol-based products on the market and formulation approaches to respond to increasing demand. Int J Pharm. 2020;584:119431 Available from: https://linkinghub.elsevier.com/ retrieve/pii/S0378517320304154.

4. European commission. Guidance on the applicable legislation for leave-on hand cleaners and hand disinfectants (gel, solution, etc.) [Internet]. 2020 [cited 2020 Apr 14]. Available from: https:// ec.europa.eu/docsroom/documents/40523.

5. Centers for Disease Control. Show me the science - when \& how to use hand sanitizer in community settings [Internet]. 2019. Available from: https://www.cdc.gov/handwashing/showme-the-science-hand-sanitizer.html\#twenty.

6. FDA. Temporary policy for manufacture of alcohol for incorporation into alcohol-based hand sanitizer products during the 
public health emergency (COVID-19) guidance for industry [Internet]. 2020. Available from: https://www.fda.gov/regulatoryinformation/search-fda-guidance-documents/temporary-policymanufacture-alcohol-incorporation-alcohol-based-handsanitizer-products-during.

7. World Health Organization. WHO guidelines on hand hygiene in health care: first global patient safety challenge clean care is safer care. World Health Organization, 2009.

8. Grispoldi L, Giglietti R, Traina G, Cenci-Goga B. How to assess 371 in vitro probiotic viability and the correct use of neutralizing 372 agents. Front Microbiol Frontiers Media SA. 2020;11:204. https://doi.org/10.3389/fmicb.2020.00204.

9. Rossitto PV, Cullor JS, Crook J, Parko J, Sechi P, Cenci-Goga BT. Effects of UV irradiation in a continuous turbulent flow UV reactor on microbiological and sensory characteristics of cow's milk. J Food ProtInternational Association for Food Protection. 2012;75:2197-207.

10. Union E. Regulation (EU) No 528/2012 of the European Parliament and of the Council of 22 May 2012 concerning the making available on the market and use of biocidal products. Off J Eur Union L. 2012;167:1-116.

11. Union E. Regulation (EU) No 1223/2009 of the European Parliament and of the Council of 30 November 2009 on cosmetic products. Off J Eur Union L. 2009:342:59-209.

12. FDA. Coronavirus (COVID-19) Update: FDA reiterates warning about dangerous alcohol-based hand sanitizers containing methanol, takes additional action to address concerning products [Internet]. FDA NEWS RELEASE. 2020. Available from: https://www.fda.gov/news-events/press-announcements/coronavirus-covid-19-update-fda-reiterates-warning-about-dangerousalcohol-based-hand-sanitizers.

13. Kampf G. Efficacy of ethanol against viruses in hand disinfection. J Hosp Infect. 2018;98:331-8 Available from: http:// www.sciencedirect.com/science/article/pii/S0195670117304693.

14. Mahdizadeh S, Sawford K, van Andel M, Browning GF. Efficacy of citric acid and sodium hypochlorite as disinfectants against Mycoplasma bovis. Vet Microbiol. 2020;243:108630 Available from: http://www.sciencedirect.com/science/article/pii/ S0378113519315056.

15. Kampf G, Kramer A, Suchomel M. Lack of sustained efficacy for alcohol-based surgical hand rubs containing 'residual active ingredients' according to EN 12791. J Hosp Infect. 2017;95:1638 Available from: http://www.sciencedirect.com/science/article/ pii/S0195670116305217.

16. Kampf G. Biocidal agents used for disinfection can enhance antibiotic resistance in gram-negative species. Antibiotics. 2018;7:110.

Publisher's Note Springer Nature remains neutral with regard to jurisdictional claims in published maps and institutional affiliations. 